or three years old), small fields with a considerable quantity of hummocky ice prevailing. In the region of the North Pole, old comparatively level fields were the most common. At least a year or more is necessary for the Sedov ice to be transformed into fields of this kind.

When flying from Franz Josef Land to the North Pole, the Soviet airmen first saw a belt of comparatively young ice. This was followed near lat. $86^{\circ} \mathrm{N}$. by a peculiar belt of hummocky or jagged ice, the origin of which has not been sufficiently studied. Level fields of old ice stretched beyond this belt to the Pole itself.
To judge by the data at our disposal, the Sedov is in the belt of hummocky ice situated between the main mass of Arctic ice and the ice carried comparatively recently into the central basin from the seas of the Soviet Arctic. This would explain the constant movement and jamming of the ice observed by the Sedov expedition.

Finally, it is possible that the belt of hummocked ice stretches along the trough of low pressure created by the inrush of masses of Atlantic air into the Arctic. This is all the more probable since the passage of this air is usually accompanied by powerful winds.

\title{
Medical Research in Great Britain
}

$\mathrm{F}^{\mathrm{O}}$ $\mathrm{R}$ those who desire to obtain some conception of the progress of medical research in Great Britain, no better means can be suggested than a perusal of the latest annual report of the Medical Research Council*. Subjects to which the Council wishes to direct special attention are reviewed in the introduction; the remainder of the report falls naturally into several sections describing work carried out for different Government Departments, at the National Institute for Medical Research (including the Department of Biological Standards), by members of the Council's external scientific staff, and in clinical research units and in hospitals and other institutions by investigators aided by grants. The Council also awards research fellowships in tropical medicine, Rockefeller medical fellowships and Dorothy Temple Cross research fellowships in tuberculosis. During the year, Prof. A. J. Clark and Sir John Ledingham retired from the Council and Prof. C. R. Harington and Prof. W. W. C. Topley were appointed to succeed them.

The report mentions that a beginning has been made with the work of construction of the new National Institute for Medical Research at Mill Hill, to which reference was made in last year's report. At least two years, however, will be required for completion. The new Institute will provide accommodation for the central laboratory under the national scheme for research in chemotherapy, of which an account was also given last year. At present, research work is being gradually developed by selected investigators at different centres, the Council having assumed responsibility for supporting the chemical as well as the biological investigations: previously the former were supported by the Department of Scientific and Industrial Research. The policy of transferring

* Committee of the Privy Council for Medical Researeh. Report of the Medical Research Council for the Year 1937-38. (Cmd. 5939.) Pp. 221. (London: H.M. Stationery Office, 1939.) 38. 6d. net. the Institute to Mill Hill has involved reconsideration of the proposed memorial to the late Sir Walter Fletcher. The original intention was to apply the balance of the fund, after providing the personal memorial, towards a new laboratory for research on nutrition at Mill Hill. With the transference of the Institute, this laboratory, instead of being the chief building on the site, will occupy only a relatively subordinate position. It has been decided, therefore, with the agreement of the subscribers to the fund, to devote it to the provision of a hall for meetings and lectures as an addition to the new Institute. The Council will meet the whole cost of the nutrition laboratory.

The Council points out that, during the past twenty-five years, since the Medical Research Committee was first set up, there has been a great increase in knowledge of the body in health and disease, greater even than that of the previous twenty-five years. This new knowledge has had two influences which, in their effect on medical practice, are often opposed to each other. In the first place it has resulted in a great improvement in methods of diagnosis and treatment of disease, which has involved a vast increase in medical services. Many patients suffering from diseases which, twenty-five years ago, were incurable and uncontrollable can now be restored to health and well-being. At the same time new knowledge of curative treatment may in itself also bring about reduction in incidence of disease; for example, the more rapid and effective cure of gonorrhœea by drugs of the sulphanilamide group should result in a reduction in its incidence by reducing the spread of the infection. Recent results also give hope that these drugs may lead to reduction of the number of cases of middle ear disease, which is responsible for a large proportion of the cases of disabling deafness in Great Britain. 
On the other hand, medical research has brought another kind of knowledge which, properly used, leads directly to the prevention and elimination of disease. The effect on medical practice is clearly opposed to the first-mentioned effect, since, by eliminating disease, it tends to reduce the needs for curative aids. The report points out that there is often great delay in bringing about the application of new discoveries to preventive ends. Fresh means of curative treatment, on the other hand, are generally applied within a short period of their discovery. This delay is considered to be due to the fact that there is no means of educating the public in the established advances in preventive medicine. It is responsible for much unnecessary suffering. The report illustrates this point by reference to the prevention of diphtheria and to the value of improved nutrition. Where preventive inoculation with diphtheria toxoid has been generally adopted, diphtheria as a clinical entity has practically disappeared: yet in 1937 there were more than 61,000 cases in England and Wales, with almost 3,000 deaths. The report urges parents to demand this prophylactic inoculation for their children, and considers that there is no doubt that its general adoption would lead to the virtual disappearance of the disease from Great Britain.

The need for improved nutrition has been discussed in previous reports, but the adoption of modern teaching in the subject is still depressingly slow : a much greater consumption of milk and other dairy products, of eggs, vegetables and fruit and of fat fish at the expense of bread, biscuits, sugar and sweets, will improve the physique of the people, reduce the amount of dental decay and greatly raise the standard of health. An increased consumption of the 'protective' foods would also be of great economic value to the country.

The Council is sometimes asked what is its policy in promoting research : whether it favours research on disease itself rather than on more academic problems of physiology and biochemistry. The general answer is that it welcomes both kinds of investigation. Promotion of specific research by the Council is usually done by appointment of individuals to its permanent staff, the choice depending on the subject which seems to require special attention and the merits of the person chosen. Thereafter the individual has wide liberty of action in planning investigation. The Council seldom chooses particular diseases for investigation ; generally the choice is of a wider nature, to include study of an etiological factor common to a group of diseases, or a type of treatment of wide application ; in fact, such subjects as virus diseases, endocrinology or chemotherapy. For another large part of the work helped by the Council by means of personal and expenses grants, the initiative in choice of subject and method of investigation lies with the head of the laboratory in respect of some individual worker, or with the worker himself. The Council considers that at the present time there is a relatively great dearth of work in clinical science and in experimental pathology, so that it is offering scholarships and fellowships to attract young investigators into these particular fields of inquiry.

An important duty of the Council is to help Government departments confronted with immediate problems of health and disease in the course of their work. The report describes briefly some of the main investigations now being made. Important research on nutrition in the Colonial Empire has been carried out in association with the Colonial Office. In Nyasaland, the dietetic and nutritional conditions of the people are being accurately assessed and related to other surveys of the agricultural and social conditions. It is hoped thereby to determine methods of producing those agricultural products which will cause a great improvement in the physical condition of the population. It is also hoped that this survey may form a model for many similar studies elsewhere in the Colonial territories. Other investigations made for Government departments relate to the nature and causes of chronic lung disease in coal miners, and to the dangers to health which may follow the use of certain organic substances as solvents in industry. Research has been made into the best methods of ridding houses of the bed-bug; it is hoped by this work to discover new insecticides for the purpose which are rapid in action, safe and cheap ; good results have already been reported from fumigation with heavy naphtha.

The report describes results obtained in the treatment of cancer of the mouth, tongue, pharynx and larynx by radium beam therapy; most of the patients have been in an advanced and inoperable stage of cancer, but the results appear to compare favourably with those to be expected from surgery. Of even greater importance than the actual therapeutic results are the new technical methods which have been elaborated as the result of close co-operation between physicists and clinicians : they are already being widely used as models to be followed in researches in radiotherapy at other centres.

For the student of medicine and the specialist, the descriptions of recent researches on the hormones, the vitamins and virus diseases should prove of particular interest. It is pointed out that as a result of intensive chemical researches in the last few years, new synthetic substances having actions closely simulating those of some of the 
natural hormones have been produced in the laboratory and made available for the treatment of disease. Thus diethylstilbœstrol is a synthetic oestrogen which is active by mouth and is already finding a place in treatment. A lengthy account of the physiological action of different hormones is given in the section of the report devoted to work carried out at the National Institute.

This summary is intended only to give a general idea of the work and policy of the Medical Research Council : brief reference has also been made to a few subjects in which there have been recent advances in knowledge. The interested reader will find in the report full references to all the researches carried out under the auspices of the Council, which have been published in the scientific journals, as well as mention of the many investigations still in progress.

\section{Observation of the Sun's Corona and Prominences without Eclipses}

M BERNARD LYOT, of the Astrophysical 1. Section of the Paris Observatory, delivered the George Darwin Lecture before the Royal Astronomical Society on May 12, the subject being "A Study of the Solar Corona and Prominences without Eclipses". To this research, M. Lyot has made unique and fundamental contributions for which he has been awarded this year the Royal Astronomical Society's Gold Medal. The presentation of the Medal was made prior to the lecture by the president of the Society, Prof. H. C. Plummer, who spoke of the medallist's great achievement in recording for the first time the sun's corona without an eclipse.

M. Lyot began his lecture with a brief review of past attempts made by various investigators from 1878 onwards to record the solar corona without a total eclipse of the sun. Direct photography from high altitude sites, thermo-electric, spectroscopic and polariscopic methods had all been tried but gave negative results. In consequence, the problem was generally regarded as being beyond the range of observational technique. Ten years ago, M. Lyot, encouraged by the advice of the late Prof. H. O. Barnard of the Colombo Observatory, made a fresh attempt to record the corona in full sunlight.

Measurements made during total solar eclipses showed that the brightness of the corona at $2^{\prime}$ from the sun's edge was only about one-millionth that of the light from the disk. To obtain any success, it was therefore a primary necessity to reduce to a negligible amount the diffusion of light by the optical train of the telescope. This diffused light in an ordinary telescope is at least two hundred times greater than the inner coronal image. Furthermore, the whitish aureole of diffracted light around the sun produced by dust in the earth's lowest atmosphere and by ice crystals of cirrus cloud is generally in itself more than a hundred times brighter than the corona.
To overcome the first difficulty, M. Lyot constructed with increasing success three special coronographs. To avoid the dust, he took his apparatus to the Pic du Midi in the Pyrenees at a height of 2,870 metres, where excellent conditions on cloudless days are obtained especially in the late spring.

The general plan on which the coronographs were constructed is as follows: A single planoconvex lens $(A)^{*}$ forms an image of the sun on a blackened disk of brass projecting just beyond the image by $15^{\prime \prime}-20^{\prime \prime}$. A field lens placed behind the disk produces an image of the lens $A$ in a diaphragm, the edge of which intercepts the light diffracted by $A$. A small screen placed in the centre of the diaphragm intercepts the light of the solar image produced by reflection from the surfaces of $A$. Behind the diaphragm and the screen, protected from the diffused light, an overcorrected objective forms an achromatic image of the corona on the plate. The whole optical train is contained in a tube, open only during the observations and coated inside with thick oil to trap the particles of dust. The primary lens must be wiped frequently with particular care.

M. Lyot showed a number of slides of the observatory and instruments. Even under the best conditions, the last part of the ascent of the Pic du Midi has to be made on foot. The coronographs are made to telescope into sections for manual transport often over deep snow.

\section{The Corona: Direct Photographs}

Lyot's work on the direct photography of the corona was made in two stages : (1) 1930-34, when the new method by his coronographs was being

* The two later objectives were cut from flawless disks of borosilicate crown glass produced by Messrs. Parra-Mantois. The lens of the second coronograph was ground in the Institut d'optique in Paris, while that of the third instrument was figured by $M$. Couder at the Paris Observatory. 